\title{
CARACTERIZACIÓN DE LA OFERTA COMERCIALIZADA BAJO LA ETIQUETA DE TURISMO RESPONSABLE EN ESPAÑA
}

\author{
Francesc González Reverté \\ Universitat Oberta de Catalunya \\ fgonzalezre@uoc.edu
}

\section{RESUMEN}

En este trabajo se establece un análisis empírico exploratorio sobre el producto de turismo responsable actualmente comercializado en España. Este producto es caracterizado a partir del vaciado de los catálogos de viajes de turismo responsable de los catorce distribuidores españoles más importantes. La oferta se caracteriza en base a su formato y precio, las prácticas de ocio realizadas y a los componentes éticos que aparecen en las prácticas durante el viaje. El principal resultado obtenido es una tipología de viajes de turismo responsable en función de sus características formales y del papel que las prácticas turísticas y de ocio tienen en su implementación.

Palabras clave: Turismo responsable, producto turístico, turismo sostenible, España.

\begin{abstract}
This paper provides an empirical analysis of the current Spanish fair tourism supply. The fieldwork consisted in analyzing fair tourism travel catalogues from 14 major Spanish distributors. The characterization of the Spanish fair tourism supply is established through the analysis of the journey structure and price, the leisure practices performed by tourists during their stay and the ethical components and social responsibility associated with the travel providers. The main result is the establishment of a typology of fair tourism trips according to their formal characteristics and the role that tourism and leisure practices have in its implementation.
\end{abstract}

Key words: Fair Tourism, tourism product, sustainable tourism, Spain.

Fecha de recepción: enero 2013.

Fecha de aceptación: noviembre 2013. 


\section{INTRODUCCIÓN. LAS PRÁCTICAS DE TURISMO RESPONSABLE EN ESPAÑA EN ELCON- TEXTO DE LA SOSTENIBILIDAD}

La incorporación de la sostenibilidad como marco paradigmático en el turismo contemporáneo se refleja en la gran cantidad de documentos que toman como punto de partida de reflexión e invitación a la acción este concepto (Cañizares, 2012). En los últimos veinte años la conciencia colectiva de la sociedad contemporánea se ha permeabilizado ante la sostenibilidad y el sistema de agentes del turismo no ha sido una excepción (Pérez, 2004). Esto ha significado la ampliación del uso, tanto retórico como aplicado, de la sostenibilidad como telón de fondo para políticas y prácticas turísticas. En este sentido, en España las recomendaciones de los organismos internacionales de referencia se han incorporado en las políticas y estrategias públicas en turismo (Torres y López Palomeque, 2012), las empresas turísticas han tomado conciencia de la necesidad de dejar puertas abiertas a la sostenibilidad, ya sea como mecanismo de greenwashing o como estrategia de competitividad (Fullana y Ayuso, 2002) y en el entorno académico se ha profundizado en la comprensión y el análisis de los elementos de medida, control y desarrollo de la sostenibilidad sobre la industria turística y en sus diferentes modalidades y prácticas recreativas y de ocio (Vera, 2001; García, 2010; Torres, 2010).

El turismo responsable enlaza directamente con las consideraciones y criterios del turismo sostenible en materia de reducción de impactos ambientales, sociales y económicos en relación a los destinos de acogida e introduce el concepto de ética en el comportamiento tanto de los productores como de los consumidores (Rivera y Rodríguez, 2012). El turismo responsable debe servir para mejorar la sostenibilidad del conjunto de la industria turística, pero establece una praxis específica que debe entenderse por la transformación de algunos elementos, tanto desde el punto de vista de la oferta como de la demanda. Entre los cambios experimentados por la demanda encontramos un perfil de turista más experimentado y participativo, mejor informado sobre los destinos que visita y de su contexto más allá de lo estrictamente turístico y que incorpora en su motivación a la vista el componente ético y formativo. Turistas más globalizados y cuya satisfacción de la visita se centra en aspectos éticos y en la personalización del viaje implican nuevos comportamientos y expectativas. Esta evolución de la demanda ha producido también una tibia reacción por parte de la oferta y han empezado a aparecer nuevos productos turísticos donde la responsabilidad es un componente central de la visita. El carácter poco proactivo se advierte ante el hecho que el turismo responsable se contempla más como un nicho de mercado que como una tendencia a generalizar al conjunto del sistema turístico, y por el hecho que la incorporación de elementos de responsabilidad social todavía se plantean a nivel de estrategia de diferenciación o de marketing.

En definitiva, el turismo responsable guarda relación con los aspectos fundamentales del desarrollo sostenible, pero llevado a sus últimas consecuencias responde mejor a la idea de movimiento social, ya que su finalidad principal es sensibilizar e incidir sobre una acción responsable de las personas que lo realizan con el objetivo de transformar el modelo turístico vigente. Si bien la sostenibilidad ha servido para informar, analizar, tomar conciencia de los problemas y proponer buenas prácticas el turismo responsable intenta dar un paso adelante más en el sentido de sensibilizar y generar empatía a través de la experiencia turística. Los turistas se entienden como un agente que «toma partido» por lo que su experiencia turística 
sólo tiene sentido si es capaz de materializarse en viajes que repercutan positivamente en la comunidad local y el destino al mismo tiempo que le aporten situaciones vitales enriquecedoras. La voluntad de transformación implica que todos los agentes se responsabilicen y puede afectar a cualquiera de las modalidades (Godwin, 2011). En este sentido, turismo responsable y turismo sostenible están relacionados pero no conllevan el mismo significado puesto que el primero tiene un carácter más «reactivo» y el segundo es más «preventivo». El turismo responsable, de hecho, implica enfrentarse al reto de hace el turismo más sostenible en función de asumir la responsabilidad que conlleva la acción. En consecuencia, la responsabilidad implica toma de conciencia y requiere algún tipo de acción (o reacción) como respuesta transformadora (Godwin, 2012).

A pesar de la connotación diferente que conlleva el turismo responsable, bajo el paraguas de la sostenibilidad se han ido perfilando diferentes modalidades de turismo que, con matices, ofrecen productos específicos bajo el cuño de la sostenibilidad social. Si bien durante las últimas décadas ha aumentado notablemente la preocupación por los aspectos e impactos ambientales del turismo el concepto de responsabilidad ha sido incorporado en fechas relativamente recientes en el discurso sobre turismo en España como uno de los puntales que permite profundizar en los aspectos sociales de la sostenibilidad. Esta inclusión obedece al reciente interés por algunos de los puntos clave del desarrollo sostenible del turismo: respeto por la identidad y autenticidad sociocultural, redistribución económica equitativa de los beneficios obtenidos, participación de todos los agentes, minimización de los impactos sociales y culturales y sensibilización social.

El concepto de responsabilidad (que etimológicamente procede del latín «responsum», relacionado con deuda u obligación) implica considerar el valor ético en las acciones individuales o colectivas. Se trata, por tanto, de un valor que actúa en el plano de la conciencia personal asumiendo una reflexión y valoración de las consecuencias de los actos realizados. Por consiguiente la persona responsable es aquella que es consciente de sus actos y responde por ellos. En el ámbito del turismo la responsabilidad se ha manifestado tanto en la aparición de nuevas orientaciones en la gestión empresarial (RSC) como en la creación de productos adaptados a las nuevas tendencias.

Los productos turísticos basados en el concepto ético de responsabilidad aprovechan el espacio vacío que la sostenibilidad social genera en la oferta turística actual. El turismo responsable no corresponde a una modalidad específica ya que puede ser aplicable a cualquier formato turístico. No obstante algunas modalidades plantean productos turísticos concretos que enlazan directamente con el imaginario de la demanda. Entre ellos se encuentra el turismo comunitario. Se trata de un formato específico cuya principal motivación es el encuentro intercultural de calidad y el mutuo interés con la población local; la producción está sustentada en la propiedad y la autogestión de los productos patrimoniales comunitarios, con arreglo a prácticas democráticas y solidarias en el trabajo y en la distribución de los beneficios generados, se diseña para obtener el bienestar de sus miembros (Maldonado, citado en (Palomo Pérez, 2006)). También se identifica directamente con criterios éticos el formato de turismo solidario. Corresponde a esta modalidad un formato específico que organiza estancias de voluntarios que incluyen, como forma de vacaciones, la ayuda para reducir la pobreza material de determinados grupos sociales, la restauración de determinados medios naturales o la investigación en ciertos campos de la sociedad o del medioambiente 
(Wearing, 2001). A diferencia del turismo comunitario se dirige a una demanda cuya motivación vacacional estriba en la visita de «lugares solidarios» o de proyectos de cooperación con la finalidad de aprendizaje, participación o colaboración a diferentes niveles.

A pesar que la imagen proyectada por ciertas modalidades o formatos se define a partir de la consideración del respeto a los principios de sostenibilidad y a criterios éticos hay que remarcar que el concepto de turismo responsable es susceptible de abarcar todo el espectro de productos turísticos. El turismo responsable implica todo producto turístico específico o sistema de producción turística en el que los turistas, actores y proveedores locales asumen una responsabilidad respecto a los destinos de acogida desde el punto de vista medioambiental, cultural y humano, reconociéndose el papel central de la comunidad local (Palomo Pérez, 2010).

El turismo responsable incide en participar de la sostenibilidad como movimiento transformador o alternativo al turismo convencional y se orienta hacia procedimientos propios del turismo justo, es decir cualquier actividad turística donde participan agentes locales, existe una distribución equitativa y transparente del valor añadido y donde se asumen los principios de sostenibilidad (Palomo Pérez, 2006). De hecho el turismo responsable se conceptualiza frecuentemente como movimiento social en favor de la consecución de un turismo sostenible (Gomis, 2009), es decir como un ideal de turismo alternativo que, más allá de la sensibilización y transformación personal a partir de las experiencias vividas por los visitantes, aspira a formar una nueva opinión colectiva crítica con el sistema capitalista y a transformar la industria turística (Gascon, J y Cañadas, E., 2005).

El creciente interés social por el consumo ético se ha visto influido por el colapso en las alternativas percibidas al capitalismo y el rechazo creciente a las opciones políticas tradicionales (Butcher, 2003). Esto ha facilitado algunos cambios sociales y en la manera de consumir. Entre ellas cabe destacar el aumento de los mercados emisores interesados por productos de turismo responsable (entre los que se encuentra el mercado español) la aparición de operadores especializados, la preocupación ética de los turistas por los impactos negativos que su visita genera en los destinos, la búsqueda de experiencias únicas por parte de los turistas, la mejora de la imagen y reputación de la empresa, el efecto positivo sobre la moral de los trabajadores y el incremento del retorno de la inversión que conlleva la introducción de métodos de gestión responsable. (Ashley, Roe, y Goodwin, 2001; Frey y George, 2008).

Resulta innegable que cada vez más la demanda opta por nuevas formas de viajar que tengan en cuenta formatos más responsables. Esto puede ser interpretado como una motivación diferente que obedece a un cambio social, pero también, de forma no excluyente con el anterior punto, como la formación de un nicho de mercado específico que pretende distinguirse socialmente no a través de la ostentación, como había ocurrido en diferentes formatos de turismo de élite anteriores, sino mediante valores sociales o culturales como la solidaridad, el contacto intercultural, la autenticidad o la experiencia y transformación personal a través del conocimiento de la realidad.

El turismo es una actividad comercial así como un fenómeno social. Los proveedores de viajes turísticos los empaquetan y comercializan para la venta al cliente final, por lo que la comprensión del comportamiento de los actores implicados, de los impactos y de la organización de los destinos se relaciona con la manera como los productos turísticos se estructuran y comercializan. Por este motivo el objetivo de nuestro trabajo es presentar una 
radiografía del actual estado de la oferta de la producción de servicios turísticos responsables en España y caracterizarlos de forma que permitan apreciar cuáles son sus componentes básicos y reflexionar acerca de su capacidad para posicionarse en el mercado. Este objetivo se pretende cubrir a partir del análisis empírico de los catálogos y programas de viajes de una muestra de diferentes agencias especializadas y ONGs que ofrecían productos de viajes de turismo responsable durante la temporada 2011 y 2012. En concreto se pretende caracterizar la oferta de turismo responsable a partir del análisis de sus diferentes atributos básicos: destinos receptores, precio, forma de organización del viaje, existencia de requisitos para la demanda y prácticas realizadas durante la estancia.

La aparición de tendencias éticas entre los mercados ha hecho surgir, por un lado, oportunidades de negocio empresarial a partir de nichos de mercado emergente. Por otro lado, la liberalización del mercado y la progresiva indiferenciación entre el ocio y el resto de ámbitos de la vida cotidiana (Urry, 2000), entre los que se cuenta también la solidaridad, permeabiliza la entrada de las ONGs en la producción de servicios turísticos. En España no existen estadísticas acerca del peso del turismo responsable en el conjunto del sector turístico, aunque algunas estimaciones apuntan a que la demanda potencial de turismo responsable emisor español hacia el extranjero se sitúa aproximadamente sobre los 500.000 turistas (Palomo Pérez, 2010).

Las expectativas de crecimiento de la demanda ha estimulado la aparición de agencias de viaje especializadas, así como la incorporación de las ONGs a la organización de viajes de turismo responsable. Esto último se ha visto favorecido por la adaptación a la normativa española de la directiva Bolkestein, que propone la supresión de las trabas y obstáculos que restringen desproporcionalmente el acceso a las actividades de servicios y a su ejercicio. En España la Ley 17/2009 de 23 de noviembre sobre el libre acceso a las actividades de servicios y su ejercicio implica la pérdida de exclusividad de la venta de servicios turísticos sueltos, es decir que no tienen las características de un viaje combinado, por parte de las agencias de viajes. Este hecho ha originado un polémico debate al considerar estas que se fomenta la competencia desleal. En contrapartida algunas ONGs trabajan conjuntamente con agencias de viaje con licencia para la comercialización del producto combinado de paquetes de viajes de turismo responsable. De este modo, la demanda de productos de turismo responsable se articula en España tanto a través de ONGs que ofrecen servicios turísticos como a partir de agencias de viaje especializadas.

Para algunos segmentos de la demanda turística española actual uno de los valores fundamentales del formato y filosofía de viajes de turismo responsable es la posibilidad de ofrecer vacaciones que se orientan más desde un punto de vista ético que comercial. En consonancia con este aspecto, para que los productos de turismo responsable puedan ejercer como puntales para generar confianza entre los consumidores y ser comercializados de forma eficiente, deben contener determinados elementos en su diseño e implementación que concuerden con las motivaciones y tendencias de la demanda.

Desde el punto de vista del producto turístico existen algunos elementos clave a tener en cuenta para que la demanda aumente la percepción sobre ellos como parte del turismo responsable. El carácter ético del proveedor de los servicios. La presencia de políticas de responsabilidad social y códigos éticos en la entidad, el recurso (o la justificación del rechazo al uso) de las certificaciones de sostenibilidad y la transparencia económica en la distribu- 
ción de beneficios de acuerdo con los principios del comercio justo son aspectos esenciales (Palomo Pérez, 1998). Un segundo elemento del producto responsable tiene que ver con las experiencias proporcionadas a los usuarios en el marco de la cercanía y relación personal con el destino visitado. La programación de actividades para el conocimiento de la comunidad local en el destino es uno de los ejes fundamentales del viaje y permite ofrecer acceso a dimensiones espaciotemporales diferentes respecto a los de un viaje convencional. Ello se enmarca, de hecho, en la consideración de cómo ubicar la figura del turista dentro de un marco de turismo alternativo ((Dernoi, 1988); (Wearing, S.L. y Wearing, M, 2006). Añadir al respecto que las interacciones cara a cara con miembros de la comunidad local durante la estancia resultan muy importantes para generar, a partir de la visita turística, un proceso de doble vía que incluye beneficios mutuos para turistas y locales (Kelly, I, 1997). Finalmente los formatos de la visita tiene que tener también un carácter especial (grupos reducidos, alojamiento no de lujo, guías locales, visita a proyectos, movilidad sostenible, etc.)

La comercialización del turismo responsable es muy escasa en España en comparación con otros países europeos. El número de agencias especializadas y de ONGs que ofrecen servicios de turismo responsable es muy reducido, como lo prueba el hecho que no existe ninguna asociación ni censo de agencias especializadas o que las sedes centrales solo se localizan en las ciudades españolas más importantes donde se concentra la demanda potencial de este tipo de turismo. La escasez de oferta puede atribuirse tanto a la lentitud del cambio de mentalidad de la sociedad española en la introducción de criterios éticos para la selección de vacaciones como a las barreras a la comercialización por parte de las agencias de viaje, de manera similar a los límites detectados entre las pequeñas empresas para adoptar criterios de sostenibilidad en su gestión (Baddeley, Font, Jamal, Dredge, etal., 2011) (El Dief y Font, 2010) (Kasim, 2007). De los resultados de una encuesta reciente aplicada al conjunto de las agencias de viaje españolas se deduce que éstas no demuestran interés por organizar viajes de turismo responsable como línea de negocio prioritaria, pero sí que se contempla en la cartera de negocios futura ya que es percibido como un mercado potencial (Fondevila, J. F. y Soliguer, A., 2012).

Actualmente la organización de viajes de turismo responsable en España va a cargo, sobre todo, de las ONGs. Este fenómeno se explica, en parte, porque la cooperación al desarrollo turístico representa cada vez una parte más significativa de la ayuda oficial al desarrollo bilateral neta en España. Las ONGs participan en el 15\% de los proyectos turísticos destinados a tal finalidad (Palomo Pérez, 2010). No obstante estas instituciones se definen ideológicamente como movimiento social y defienden el turismo responsable como un elemento integrante de la acción para la cooperación para el desarrollo que no debe vincularse a formas de comercialización ni de promoción turísticas. Este modelo contrasta con el de otros lugares como el Reino Unido o Francia, donde la comercialización de productos de turismo responsable está más extendida. A pesar de que las organizaciones no gubernamentales empezaron con planteamientos similares a los que actualmente tienen las organizaciones españolas, con el paso del tiempo se reconoció la oportunidad que el turismo responsable representa para poder continuar el trabajo de cooperación solidaria internacional a partir de fondos propios. Esta posición implica ofrecer experiencias alternativas a la demanda, como por ejemplo el turismo de voluntariado, y, al mismo tiempo, explotar nuevos nichos en la industria de la cooperación (Keese, 2011). El foco de la financiación se centra más en el voluntario y, como consecuencia de este hecho, las ONGs necesitan ofrecer un producto «vendible» como experiencia que debe ser 
comercializado para el consumidor (el voluntario). La introducción de prácticas de comercialización permite combinar la lógica altruista, inherente a la acción de las ONGs, con una visión comercial en sus operaciones necesaria para captar y satisfacer las necesidades de experiencia de la demanda. Sin embargo esta visión comercial levanta suspicacias por la posible desnaturalización de los objetivos y prácticas del turismo responsable que conlleva (Wearing, 2001).

\section{METODOLOGÍA Y ANÁLISIS DE RESULTADOS}

La información recopilada se ha obtenido a partir del vaciado de los catálogos de viajes de turismo responsable que durante el 2012 ofrecían quince de las principales ONGs y agencias especializadas españolas en este ámbito ${ }^{1}$. Para escoger la muestra se ha tenido en cuenta exclusivamente aquellas agencias o ONGs que se refieren explícitamente al turismo responsable en su cartera de viajes y que incluyen explicaciones y argumentaciones de tipo ético sobre el turismo en su misión empresarial, sus objetivos o su filosofía de trabajo. Se trata, por lo tanto, de una selección de aquellas entidades que se autorreconocen como responsables $\mathrm{y}$ ofrecen medios contrastables para organizar vacaciones de turismo responsable. En este sentido se han descartado todas aquellas agencias especializadas en turismo de aventura, étnico, ecoturismo y similares que no explicitan una apuesta o vinculación clara con los principios del turismo responsable. La muestra ha recopilado un total de 89 viajes. Aunque todos ellos actúan bajo el prisma del turismo responsable los operadores seleccionados tienen una naturaleza bastante dispar. El espectro escogido incluye desde las principales agencias que comercializan este tipo de viajes en España, así como asociaciones y ONGs que incluyen el turismo como un aspecto marginal en su modelo de funcionamiento. La información recopilada procede de los catálogos expuestos en las webs de las diferentes entidades durante el año 2012, aunque una pequeña parte de los catálogos se refieren a los realizados durante el año 2011. La base de datos elaborada se ha estructurado en cuatro apartados. En el primer apartado se recoge, a partir del descriptor básico, la representación del viaje que ofrece la propia entidad: título, autodenominación como modalidad de viaje y objetivo principal del viaje. En el segundo apartado se recogen las características del formato del viaje: duración, precio, forma de organización, transporte y movilidad hacia y en el destino, formato de la visita, forma de alojamiento, presencia o ausencia de guías y personal de soporte. En el tercer apartado se reúnen las características de la estancia. En concreto se recoge cuáles son las prácticas dominantes, qué modalidades turísticas están presentes y se cuantifican las actividades realizadas a diario durante la estancia. Debido a la imposibilidad de recoger esta última información de forma completa y exhaustiva para todos los catálogos, se ha optado por contabilizar los días totales en que se realiza cada tipo de práctica. Las actividades realizadas no se contabilizan, por tanto, en base al total de actividades del viaje, sino como días de viaje en que se incluyen. En el cuarto apartado se recogen los elementos de responsabilidad social reseñados explícitamente por las entidades: existencia de formación previa al viaje, contactos postestancia, explicación del destino del gasto del turista, certificaciones

1 Concretamente se ha analizado los catálogos de 2012 de los siguientes distribuidores: ACSUD, CERAI, FUNCAL, Fundación Vicente Ferrer, Proyecto Ecuador. SETEM, SodePau, Namasté, Tabana, Turismo responsable, Viatgers del Món, Jarit, Riki Tiki Tavi, Ismalar y Club Marco Polo. 
ambientales o de otro tipo que se dispone, existencia de proyectos de cooperación asociados al viaje, explicación sobre la minimización de impactos ambientales, económicos, sociales o culturales. Finalmente se recurre a las diferentes webs de las entidades que comercializan paquetes de turismo responsable para completar la información acerca de su filosofía o misión empresarial, así como de las características y componentes éticos sobre su actividad como organizadores de viajes responsables.

\section{II.1. Los destinos de los viajes de turismo responsable}

En primer lugar el análisis se centra en determinar cuáles son los destinos receptores del turismo responsable español con la finalidad de establecer el marco geográfico donde se desarrolla la práctica turística. El carácter ético del producto de turismo responsable incide sobre la selección de destinos y sobre el diseño de estrategias de creación de oferta acordes con las necesidades y motivaciones de la demanda. De este modo, el proceso de toma de decisiones exige buscar un balance entre aquellos criterios que se inclinan por dar preferencia a los lugares que requieren mayor atención asistencial y aquellos que favorecen o facilitan la estancia de los visitantes (Keese, 2011).

Tabla 1

DISTRIBUCIÓN DE LAAYUDA AL DESARROLLO Y VIAJES DE TURISMO

RESPONSABLE ESPAÑOLES POR GRANDES REGIONES DEL MUNDO, 2012

\begin{tabular}{|l|l|l|l|l|l|}
\hline Región & $\begin{array}{c}\text { Viajes de } \\
\text { turismo } \\
\text { responsable } \\
\text { ofrecidos por } \\
\text { distribuidores } \\
\text { españoles a } \\
\text { destinos en } \\
\text { países de la } \\
\text { región }\end{array}$ & $\begin{array}{c}\text { Presupuesto } \\
\text { de ayuda al } \\
\text { desarrollo } \\
\text { concedida a } \\
\text { la región (en } \\
\text { millones } € \text { ) }\end{array}$ & $\begin{array}{c}\text { \% del } \\
\text { presupuesto } \\
\text { de ayuda al } \\
\text { desarrollo } \\
\text { respecto al } \\
\text { total que } \\
\text { recibe la } \\
\text { región }\end{array}$ & $\begin{array}{c}\text { \% viajes } \\
\text { de turismo } \\
\text { responsable } \\
\text { en la región } \\
\text { en relación al } \\
\text { total de viajes } \\
\text { ofrecidos por los } \\
\text { distribuidores } \\
\text { españoles }\end{array}$ & $\begin{array}{c}\text { Diferencia entre } \\
\text { el porcentaje } \\
\text { de la ayuda al } \\
\text { desarrollo y el de } \\
\text { viajes de turismo } \\
\text { responsable que } \\
\text { dispone cada } \\
\text { región }\end{array}$ \\
\hline África Subsahariana & 15 & 186,1 & 21,12 & 17,6 & 3,5 \\
\hline América del Sur & 11 & 256 & 29,05 & 12,8 & 16,2 \\
\hline Asia y Pacífico & 18 & 60,1 & 6,81 & 21,7 & $-14,9$ \\
\hline Centroamérica y Caribe & 14 & 230 & 26,1 & 16,4 & 10,3 \\
\hline Europa & 1 & 0 & 0 & 1,1 & $-1,1$ \\
\hline Mediterráneo & 26 & 149,1 & 16,92 & 30,4 & $-13,4$ \\
\hline Total & 85 & 861,3 & 100 & 100 & \\
\hline
\end{tabular}

Fuente: AECID, 2011; ACA, 2011 y AACID, 2011.

La oferta de turismo responsable española recogida por la muestra se distribuye hacia un total de 30 países, aproximadamente 1/3 de los países que en 2011 recibían apoyo por parte de las principales agencias de cooperación al desarrollo españolas. El análisis de la distribución por destinos de los viajes que aparecen en los catálogos de los distribuidores españoles permite apreciar que existen algunos países (Marruecos, la India, Nicaragua o Senegal, por 
ejemplo) considerados destinos preferentes. Por lo tanto podemos afirmar que la oferta se encuentra concentrada en pocos países en relación a los que potencialmente pueden necesitar estímulos a partir del turismo responsable. Siete de los países que figuran en los catálogos de turismo responsable (un 23,3\%) no eran objeto de cooperación. Esto sugiere que el catálogo de oferta no se construye exclusivamente a partir de criterios asistenciales o de ayuda al desarrollo. El desencaje entre la inclusión o exclusión de determinados países en los catálogos de turismo responsable se explica solo parcialmente por la existencia de una demanda todavía incipiente en España. Existen además otros argumentos vinculados a la esfera del consumo (percepción de seguridad, imagen percibida por parte de la demanda y posibilidades turísticas del destino, accesibilidad respecto a los mercados emisores, etc.) que pueden influir sobre la configuración final de dicho catálogo y que requieren investigaciones específicas.

Con el fin de obtener un análisis más preciso sobre la relación entre turismo y ayuda al desarrollo se ha establecido una comparación entre la distribución del peso del monto económico de ayudas a la cooperación y el desarrollo con el peso que cada país tiene como destino turístico en los catálogos de viajes de turismo responsable examinados (véase la tabla 1). El presupuesto por regiones de la ayuda al desarrollo incluye el valor económico total de todos los proyectos financiados (ya sean de tipo turístico o de otro tipo) por parte de las agencias respectivas durante el año 2011.

Las regiones del mundo que proporcionalmente más ayuda reciben están mucho menos representadas en los catálogos turísticos de viajes. Es el caso de la región del África Subsahariana y, sobre todo, de América del Sur y Centroamérica y el Caribe. En situación opuesta se encuentran las regiones del Mediterráneo y de Asia y Pacífico. Si se compara esta misma ratio a nivel de países encontramos nuevamente importantes contrastes (véase la tabla 2). Una síntesis sencilla permite distinguir entre países «solidarizados» (aquellos que tienen mayor cuota porcentual de ayuda al desarrollo que de presencia en el catálogo turístico) y países «destino» (en situación inversa a los anteriores). En función de este criterio se distinguen cuatro tipos de países:

P1. Descatalogados: países que no se incluyen en los catálogos de turismo responsable a pesar de recibir ayuda (31 países).

P2. Destinos no asistenciales: países que se incluyen en los catálogos de turismo responsable pero que no reciben ayuda (7 países).

P3. Destinos potenciales: países que reciben proporcionalmente más ayuda que representación en los catálogos de turismo responsable (10 países).

P4. Países destino: países que reciben proporcionalmente más representación en los catálogos de turismo responsable que ayuda (13 países).

En el caso del grupo P1 se trata de países pobres que perciben ayuda al desarrollo pero que no han recibido interés por parte de las agencias y ONGs españolas que comercializan productos de turismo responsable (por ejemplo Afganistán, Mozambique o Togo) . El grupo P2 son países con capacidad de atracción turística pero que no reciben ayuda (por ejemplo India, Madagascar o Nepal), por lo que puede considerarse que el turismo ocupa el rol de la ayuda oficial al desarrollo. El grupo P3 se trata de países con elevado potencial para ser destinos de TR ya que si bien merecen la consideración de la ayuda están relativamente poco 
Tabla 2

DISTRIBUCIÓN DE LAAYUDAAL DESARROLLO Y DE LOS VIAJES DE TURISMO RESPONSABLE ESPAÑOLES POR PAÍSES, 2012

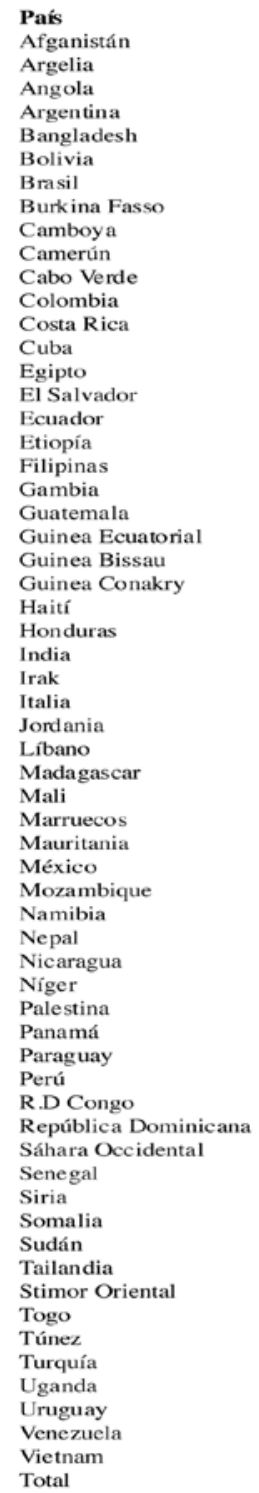

\begin{tabular}{|c|c|c|c|c|}
\hline $\begin{array}{c}\text { Programas de } \\
\text { viaje de TR } \\
\text { ofrecidos por } \\
\text { distribuidores } \\
\text { españoles }\end{array}$ & $\begin{array}{c}\text { \% sobre el } \\
\text { total de } \\
\text { programas de } \\
\text { viaje de TR }\end{array}$ & $\begin{array}{c}\text { Presupuesto de } \\
\text { Ayuda Oficial a la } \\
\text { Cooperación y al } \\
\text { Desarrollo (en } \\
\text { millones } \theta^{*}\end{array}$ & $\begin{array}{c}\% \text { sobre el } \\
\text { total de } \\
\text { AOCD }\end{array}$ & $\begin{array}{c}\text { Diferencia } \\
\text { entre el } \\
\text { porcentaje de } \\
\text { AOCD y el } \\
\text { porcentaje de } \\
\text { viajes de TR }\end{array}$ \\
\hline 0 & 0,00 & 26.2 & 2,97 & 2,97 \\
\hline 0 & 0,00 & 3.4 & 0,39 & 0,39 \\
\hline o & 0,00 & 8,6 & 0,98 & 0,98 \\
\hline o & 0,00 & 4 & 0,45 & 0,45 \\
\hline 0 & 0,00 & 2,8 & 0,32 & 0,32 \\
\hline 1 & 1,18 & 65.7 & 7,45 & 6,28 \\
\hline 1 & 1,18 & 7,1 & 0,81 & $-0,37$ \\
\hline o & 0,00 & 0,8 & 0,09 & 0,09 \\
\hline o & 0,00 & 4,8 & 0.54 & 0,54 \\
\hline 1 & 1,18 & 0.1 & 0.01 & $-1,17$ \\
\hline 0 & 0.00 & 9 & 1,02 & 1.02 \\
\hline 0 & 0,00 & 39.7 & 4,50 & 4,50 \\
\hline 3 & 3,53 & 4 & 0,45 & $-3,08$ \\
\hline 1 & 1,18 & 14,5 & 1,65 & 0,47 \\
\hline 3 & 3,53 & 1,7 & 0,19 & $-3,34$ \\
\hline 1 & 1,18 & 45,4 & 5,15 & 3,98 \\
\hline 4 & 4,71 & 42 & 4,77 & 0,06 \\
\hline 1 & 1,18 & 16.6 & 1,88 & 0,71 \\
\hline o & 0,00 & 9.7 & 1.10 & 1,10 \\
\hline o & 0,00 & 3.4 & 0,39 & 0,39 \\
\hline 2 & 2,35 & 42,7 & 4,85 & 2,49 \\
\hline o & 0,00 & 9.6 & 1,09 & 1,09 \\
\hline o & 0,00 & 7.4 & 0,84 & 0,84 \\
\hline 0 & 0,00 & 2,7 & 0,31 & 0,31 \\
\hline 0 & 0,00 & 24,5 & 2,78 & 2,78 \\
\hline 0 & 0,00 & 23,7 & 2,69 & 2,69 \\
\hline 9 & 10,59 & 0 & 0,00 & $-10,59$ \\
\hline 0 & 0,00 & 0,1 & 0,01 & 0,01 \\
\hline 1 & 1,18 & 0 & 0,00 & $-1,18$ \\
\hline 1 & 1,18 & 3.9 & 0,44 & $-0,73$ \\
\hline 0 & 0.00 & 12.6 & 1.43 & 1,43 \\
\hline 1 & 1,18 & 0 & 0.00 & -1.18 \\
\hline 1 & 1,18 & 14.3 & 1,62 & 0,45 \\
\hline 17 & 20,00 & 39,3 & 4,46 & $-15,54$ \\
\hline 1 & 1,18 & 14,8 & 1,68 & 0,50 \\
\hline 1 & 1,18 & 7,2 & 0,82 & $-0,36$ \\
\hline 0 & 0,00 & 35,8 & 4,06 & 4,06 \\
\hline 0 & 0,00 & 3,6 & 0,41 & 0,41 \\
\hline 4 & 4,71 & 0 & 0,00 & $-4,71$ \\
\hline 5 & 5,88 & 46.5 & 5.28 & $-0,61$ \\
\hline 0 & 0.00 & 6.9 & 0.78 & 0,78 \\
\hline 1 & 1,18 & 53,6 & 6,08 & 4,91 \\
\hline 1 & 1,18 & 2.6 & 0,30 & $-0,88$ \\
\hline o & 0,00 & 17,1 & 1,94 & 1,94 \\
\hline 4 & 4,71 & 70,6 & 8,01 & 3,31 \\
\hline 0 & 0,00 & 29,1 & 3,30 & 3,30 \\
\hline 0 & 0,00 & 18,9 & 2,14 & 2,14 \\
\hline 2 & 2,35 & 16,3 & 1,85 & $-0,50$ \\
\hline 10 & 11,76 & 26,5 & 3,01 & $-8,76$ \\
\hline 0 & 0,00 & 2 & 0,23 & 0,23 \\
\hline 0 & 0,00 & 2.3 & 0,26 & 0,26 \\
\hline 0 & 0.00 & 9.3 & 1,06 & 1,06 \\
\hline 1 & 1,18 & 0 & 0,00 & $-1,18$ \\
\hline 0 & 0,00 & 4,3 & 0.49 & 0.49 \\
\hline 0 & 0,00 & 0,1 & 0,01 & 0,01 \\
\hline o & 0,00 & 1,5 & 0,17 & 0,17 \\
\hline 1 & 1,18 & 0 & 0,00 & $-1,18$ \\
\hline 1 & 1,18 & 0 & 0,00 & $-1,18$ \\
\hline 0 & 0,00 & 4,6 & 0,52 & 0,52 \\
\hline 1 & 1,18 & 5,2 & 0,59 & $-0,59$ \\
\hline 4 & 4,71 & 12.2 & 1,38 & $-3,32$ \\
\hline 85 & 100,00 & 881,3 & 100,00 & 0,00 \\
\hline
\end{tabular}

*El total incluye la suma del presupuesto destinado por las siguientes Agencias de Cooperación al Desarrollo: AECID; ACA y ACC.

Fuente: AECID, 2011; ACA, 2011 y AACID, 2011. 
representados en los catálogos turísticos (es el caso, por ejemplo, de Bolivia, Cuba o Mauritania). Finalmente, el grupo $\mathrm{P} 4$ incluye aquellos países preferentes y consolidados puesto que son objeto de representación en el catálogo turístico por encima de la aportación de la ayuda (forman parte de este grupo, por ejemplo, Camerún, Brasil o Egipto). Existiría a demás un quinto grupo de países, países «invisibles», que no están representados ni en los catálogos de vacaciones de turismo responsable ni en la ayuda oficial al desarrollo.

Figura 1

DESTINOS DE VIAJES DE TURISMO RESPONSABLE QUE APARECEN

EN LOS CATÁLOGOS DE DISTRIBUIDORES ESPAÑOLES, 2012

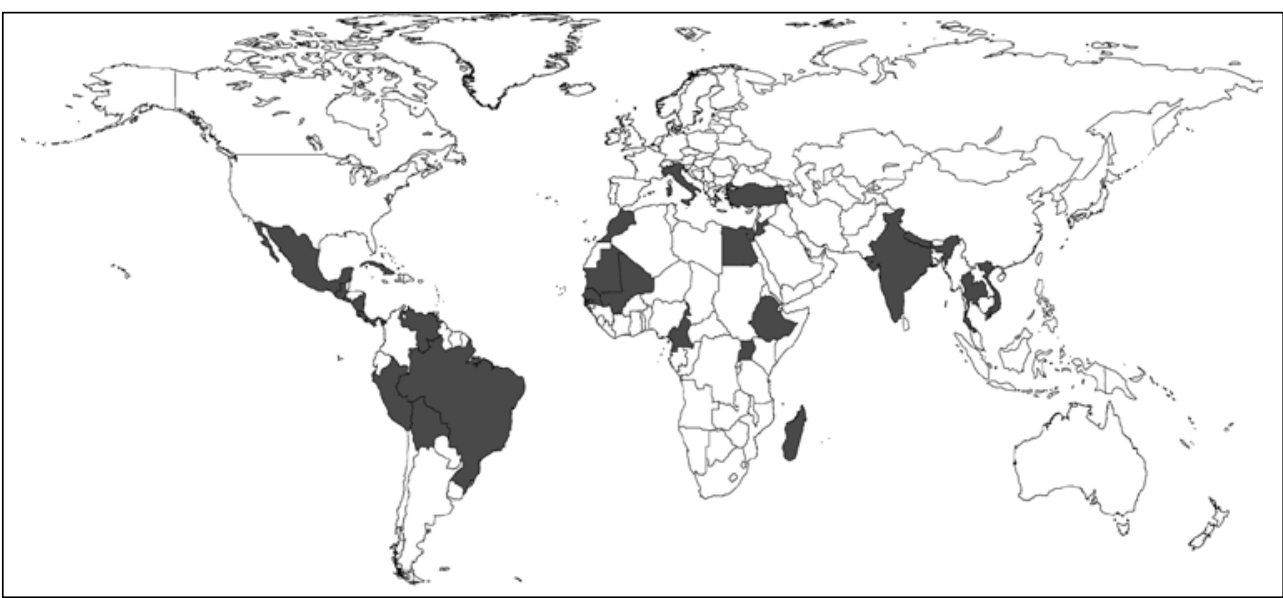

Fuente: Elaboración propia a partir de los catálogos electrónicos y de las páginas webs de los distribuidores.

Figura 2

DISTRIBUCIÓN POR PAÍSES DE LOS VIAJES DE TURISMO RESPONSABLE ORGANIZADOS DESDE ESPAÑA, 2012

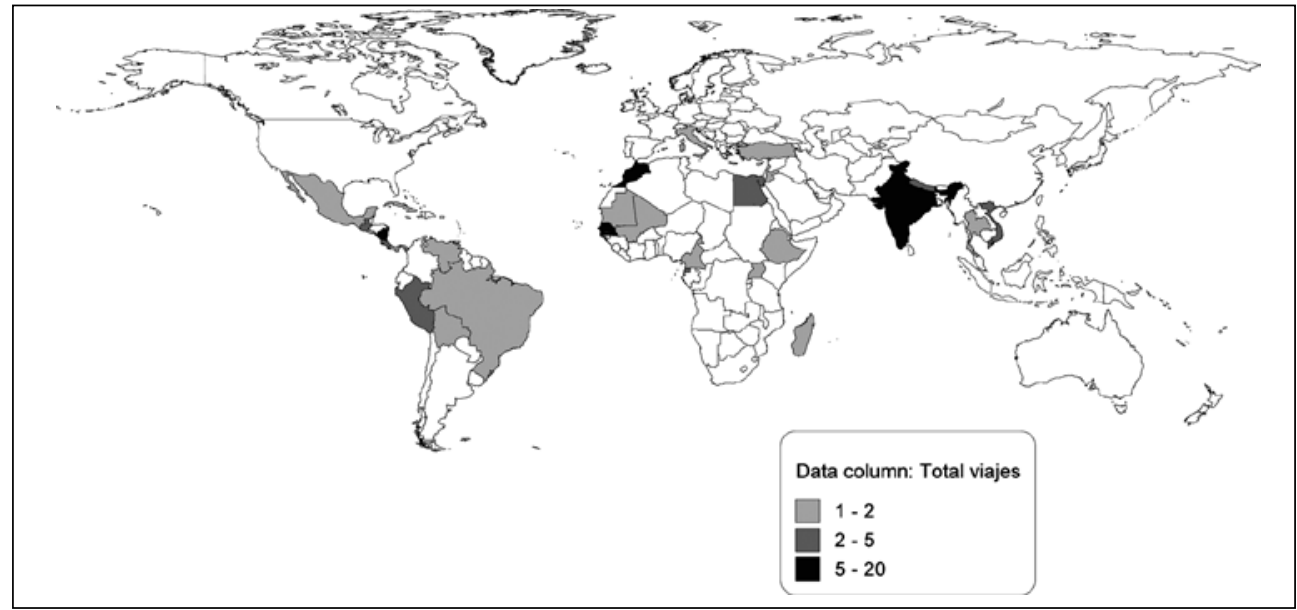

Fuente: Elaboración propia a partir de los catálogos electrónicos y de las páginas webs de los distribuidores. 
Los países con mayor representación en el catálogo de turismo responsable son Marrue$\cos (19,8 \%$ del total), Senegal $(11,6 \%)$, India $(10,5 \%)$, Nicaragua $(5,8 \%)$, Ecuador, Perú, Nepal y Vietnam (4,7\% cada uno) (véase la figura 2). La concentración de los países como destino de turismo responsable es notable, puesto que menos de diez países reúnen más de la mitad de la oferta total $(66,5 \%)$. Esta situación sugiere que no existe un factor único que condiciona la toma de decisiones en la selección de destinos, sino una mezcla de varios criterios. Por ejemplo la distancia y la accesibilidad (que habitualmente se traducen en menores costes de transporte) y los aspectos geopolíticos influyen sobre la presencia de Marruecos como destino principal. También la proximidad histórico cultural de España con América Latina contribuye a explicar la abundancia de países de esta región en los destinos de turismo responsable. En cambio, las preferencias y el enfoque de la misión de las entidades que organizan los viajes explican la inclusión de lugares como Palestina o el Sáhara Occidental entre los destinos de turismo responsable. En cambio la inclusión de países como Vietnam, India o Turquía obedecen sobre todo a consideraciones basadas en la percepción sobre las preferencias del consumidor.

\section{II.2. Caracterización de los distribuidores y del formato de los viajes de TR existentes en España (2012)}

Las agencias encargadas de comercializar los viajes de turismo responsable tienen una estructura de PYME y un carácter altamente especializado dentro del sector de la intermediación de viajes turísticos. Por su parte las ONGs disponen de poco personal destinado exclusivamente al turismo responsable y, además, no tienen como único objetivo fomentar el desarrollo a través del turismo, sino que éste constituye un instrumento más para dar sentido a su misión y filosofía. La reducida dimensión de las plantillas laborales y la especialización en segmentos de mercado minoritarios son dos de los motivos que explica el hecho que los catálogos de viajes analizados sean muy reducidos por norma general. La dimensión media del catálogo de viajes de turismo responsable es de 6,1 propuestas de viaje, el valor máximo es de 22 y el mínimo de 1 sola propuesta. De hecho, y con la excepción de dos casos, la mayor parte de los distribuidores presentan menos de 10 propuestas de viaje de turismo responsable. No obstante las agencias/ONGs con un catálogo superior a las 10 propuestas asciende hasta 4 si tenemos en cuenta otros tipos de catálogos de viajes ofrecidos no exclusivamente de turismo responsable. Por lo tanto, si tenemos en cuenta el volumen de viajes ofrecidos en el catálogo se advierte que existe una diversidad de situaciones entre distribuidores. Algunos de ellos están muy especializados en ofrecer pocos lugares como destino y tienen un número de viajes limitado, mientras que otros tienen un catálogo de viajes relativamente abundante.

Es interesante establecer esta distinción puesto que sugiere dos aproximaciones diferentes al turismo por parte de los distribuidores. En un caso se trata de distribuidores, especialmente agencias de viaje especializadas, que se plantean dar cierta amplitud a su catálogo como forma de ampliar el alcance de su público objetivo o para ofrecer alternativas de destinos a la demanda. En el segundo modelo se trata básicamente de ONGs que organizan viajes de turismo responsable como apoyo para la realización de proyectos de cooperación y donde el viaje de turismo responsable está supeditado a la localización geográfica de los proyectos. 
Además del reducido volumen del catálogo los distribuidores españoles de viajes de turismo responsable se caracterizan también por tener una limitada variedad geográfica de destinos incluidos en su oferta. De hecho prácticamente la mitad de los distribuidores ofrecen viajes de turismo responsable a un solo país. Para medir la variedad de destinos ofrecidos hemos construido un coeficiente de variedad geográfica de la oferta, donde se relaciona el número total de viajes a países diferentes ofrecidos en el catálogo con el número total de viajes ofrecidos por una entidad distribuidora. El coeficiente se expresa en porcentaje y oscila de 0 a 100 (donde 0 indica que se ofrecen viajes a un único destino y 100 indica que todos los viajes se realizan en destinos diferentes). Un $43 \%$ de los distribuidores tienen un coeficiente de variedad elevado y el valor promedio del coeficiente para toda la muestra analizada es de $60,5 \%$ por lo que puede considerarse que la variedad en la programación de viajes es relativamente elevada (véase la tabla 5). Resulta también pertinente aquí la distinción entre modelos de distribuidores establecida al comentar el volumen del catálogo. Tan solo tres distribuidores tienen un catálogo con amplia variación geográfica (coeficiente mayor de 80) mientras que el resto se especializa en uno, dos o tres países, sobre todo debido al hecho que realizan viajes con la finalidad de apoyar proyectos de cooperación concretos. El análisis del formato de los viajes de turismo responsable ofrecidos en los catálogos se basa en aspectos básicos del mismo como la duración, el precio, el formato de comercialización, el tipo de alojamiento o la forma de movilidad en el destino. La duración media del viaje de turismo responsable es de 12,3 días, cifra sensiblemente superior a la de otros tipos de vacaciones convencionales. No obstante el registro de frecuencias de la duración del viaje contiene valores heterogéneos que oscilan entre las estancias breves y/o fines de semana (3 días) y las estancias, poco habituales, de un mes de duración. Esta variedad responde a diferentes propuestas y motivaciones subyacentes en cada formato de viaje, aspecto que subraya la variedad de formatos existentes que se esconden bajo el paraguas de turismo responsable. De todos modos solamente un $11 \%$ de los viajes tienen una duración inferior a una semana, mientras que los viajes de duración intermedia (de 7 a 15 días) representan el $66 \%$ y los de larga duración (más de 15 días) el 23\% restante. La larga duración de la estancia se relaciona con el interés por organizar viajes donde se prolongue el contacto con el destino, la población local y/o las comunidades de acogida en cualquiera de los posibles modos (tour, solidaridad, colaboración, contacto intercultural, etc.).

Un elemento fundamental en el análisis realizado es el coste del viaje. El precio del paquete básico del viaje de turismo responsable (sin incluir el transporte al destino) es de $998 €$, mientras que asciende a $1.873 €$ si se incluye el precio estimado del transporte al destino (véase la tabla 3). Se trata de un precio elevado en relación a un viaje vacacional convencional puesto que en turismo responsable se apuesta por organizar grupos pequeños de visitantes, cosa que no permite la obtención de cupos en los vuelos y, además, muchos de los destinos resultan lejanos respecto a los lugares de origen, aspecto que encarece el coste de transporte y repercute en el precio total final.

El precio es un elemento decisivo en la compra de un paquete turístico por lo que el valor medio de los viajes de turismo responsable actúa como un límite a la expansión social de este tipo de viajes. De hecho tan solo un $22 \%$ de los paquetes analizados tienen precios inferiores a los $500 €$ y un $34 \%$ ascienden a más de $1.000 €$. El valor medio por día de viaje matiza un tanto la anterior observación. La mayor duración del viaje en relación a los 
Tabla 3

PRECIO MEDIO DEL VIAJE DE TURISMO RESPONSABLE, 2012*

\begin{tabular}{|l|l|l|}
\hline & Precio medio & Precio medio por día \\
\hline Paquete básico & $998,00 €$ & $88,10 €$ \\
\hline Paquete básico + transporte** & $1.873,00 €$ & $129,70 €$ \\
\hline
\end{tabular}

* La muestra de viajes donde consta la información del precio es de $\mathrm{n}=53$.

** Estimado en base a las tarifas de transporte aéreo al destino más económicas ofrecidas durante el mes de octubre de 2012 .

Fuente: Elaboración propia a partir de los catálogos electrónicos y de las páginas webs de los distribuidores.

estándares habituales hace que el valor medio del precio diario no se aleje en exceso de la de otros tipos de oferta convencional. No obstante, y más allá de otro tipo de preferencias y factores motivacionales de la demanda, pensamos que el valor absoluto del gasto realizado continua ejerciendo como factor que limita al acceso social de muchas capas de la población a este tipo de viajes. El precio elevado, el hecho de que el turismo responsable se centre en un público objetivo todavía muy reducido en relación a la demanda turística total, la lejanía de algunos de los destinos respecto a los lugares emisores así como la falta de accesibilidad a los mismos resultan factores que convierten a los viajes de turismo responsable en una práctica minoritaria. De hecho algunos componentes del viaje de turismo responsable refuerzan el imaginario del viajero alternativo pero elitista, donde lo alternativo se mezcla con lo exclusivo, en especial en lo referente al precio, el carácter pionero del viaje y la lejanía y/o exotismo de algunos destinos.

La estancia en el destino se realiza mayoritariamente en el formato de itinerario, ruta o circuito de visita. En concreto un $88,8 \%$ de los programas de viaje incluyen un circuito de visitas, mientras que un $27 \%$ consisten en estancias fijas en un solo destino (vinculadas especialmente al turismo de voluntariado pero que no excluyen visitas y excursiones a lugares cercanos) y en un $12,4 \%$ de los viajes se incluyen estancias en campamentos solidarios o similares. En resumen, las estancias se organizan en base al tour como formato de viaje, aspecto que permite asociarlas a un carácter viajero y nómada. No obstante la estancia en movimiento constante implica, por un lado, la necesidad de cubrir diferentes etapas por lo que la continuidad del contacto directo con las comunidades locales y los actores del destino se ve mermada, hecho que limita las posibilidades de conocimiento de la realidad local. El recurso al tour explica que la movilidad en el destino sea notable. Este aspecto, juntamente con la dificultad de accesibilidad en el interior de determinados destinos (infraestructuras de transporte en malas condiciones, dificultad de acceso a los destinos desde el aeropuerto en transporte público, etc.), justifica que la organización del viaje se realice de forma mayoritaria mediante transporte privado (furgonetas, minibuses turísticos, vehículos de $4 \times 4$ etc.). En contraste, el transporte público solo está presente en el $36,6 \%$ de los viajes. Además, en muchos casos, la lejanía respecto a los lugares emisores hace imprescindible el uso del avión privado. De hecho en un 92,1\% de los viajes el avión es el medio de transporte al destino principal y en un $18 \%$ de los viajes es utilizado como medio de transporte entre destinos de un mismo viaje. Este aspecto es uno de los más controvertidos en relación a la sostenibilidad ya que probablemente el consumo de combustible derivado del uso del avión como forma de transporte dominante 
implica efectos en relación al aumento de la huella ecológica y contribución al cambio climático superiores a los efectos de las medidas paliativas ambientales durante el viaje.

La organización de la visita se estructura en paquetes comercializados que incluyen alojamiento, visitas durante la estancia y desplazamientos interiores. El transporte al destino, en cambio, va frecuentemente a cargo del cliente. En algunos casos se da la opción al cliente de escoger entre algunas opciones de visita o de ir por libre en alguna parte del itinerario o en todo él $(7,9 \%)$, pero por lo general se trata de itinerarios cerrados con visitas programadas (en el 96,6\% de los viajes). En los casos donde existe espacio para la programación libre la mayoría de veces responde a tardes o mañanas libres para ultimar compras o para descansar, siendo mucho más escasas los días libres completos o para organizarse parte del itinerario en el destino de forma complementaria o paralela a la programada por la agencia o ONG. Además, queda muy claro que se trata de un viaje organizado para grupos $(93,3 \%)$ aunque en muchas ocasiones se organizan viajes a partir de dos personas. Los grupos acostumbran, no obstante, a ser de tamaño reducido (menos de 20 personas).

El tipo de alojamiento predominante en los viajes de turismo responsable es el hotelero, presente en un $86,5 \%$ de los viajes. Hay que matizar este dato puesto que en buena parte de los viajes se ofrece este tipo de establecimiento básicamente como pernoctación en la primera y/o última noche de estancia. No obstante durante el itinerario de visita al destino también se utiliza profusamente, especialmente en sus categorías media y media-baja. Los alojamientos turísticos no hoteleros reglados constituyen el segundo tipo de alojamientos más empleados $(49,4 \%)$ e incluyen una amplia gama de formatos (cámpings, bungalows, ecolodges, casas rurales, etc.). Los alojamientos en casas particulares se ofrecen en un 39,3\% de los viajes, aunque normalmente se trata de alojamientos ocasionales en el marco del itinerario. Los alojamientos comunitarios (campamentos, refugios, albergues, habitaciones de huéspedes, etc.) se incluyen en un 34,8\% de los viajes, mientras que las estancias en campamentos de voluntarios están presentes solamente en el 11,2\% de los viajes. La incomodidad en este tipo de viajes puede ser considerada como un aliciente por determinados segmentos de la demanda pero, evidentemente, supone un obstáculo para la mayor parte de ella. Por eso existen ciertos guiños hacia la demanda más «exigente» en las condiciones de viaje establecidas en los catálogos: en algunos viajes se posibilita disponer de habitaciones individuales o baño a cambio de un suplemento, se prioriza la estancia en establecimiento turístico antes que en la de los locales si estos no alcanzan los mínimos de comodidad e higiene occidentales, se permite, previo pago de suplemento, el uso de habitaciones individuales o dobles en alojamientos de tipo comunitario, etc.

En resumen, la oferta hotelera o reglada consta en más de la mitad de los viajes, y con frecuencia es la forma de alojamiento principal durante el circuito, aunque normalmente se combina con otros formatos. El alojamiento en casa de particulares locales cumple una doble misión. Por un lado facilita el intercambio y la convivencia entre turistas y miembros de la comunidad local (por lo que puede ser considerado una práctica turística más dentro del programa de visitas) y, en algunas ocasiones, minimiza el papel de los intermediarios. Por otro lado también representa un recurso en destinos remotos o sin infraestructura turística cuando no se tiene acceso a otras formas de alojamiento. Finalmente el alojamiento en campamentos de voluntarios es poco frecuente ya que son escasos los viajes de turismo responsable que se centran en el turismo de voluntariado. 
El formato de viaje de turismo responsable en paquete para grupos, en forma de tour, con una programación planificada y cerrada o semi-cerrada de la visita pensado para grupos y con alojamiento hotelero son aspectos que se asemejan al de los viajes de vacaciones convencionales. El carácter colectivo y gregario y la escasa capacidad de opciones personales en la programación del viaje puede ser interpretado no solo como un elemento de protección ante riesgos del destino sino también como mecanismo de control de la visita o orientación de la misma. Este aspecto se complementa también con la presencia de guías turísticos $(94,4 \%)$ (mayoritariamente profesionales locales o miembros de la comunidad local del destino conocedores del entorno).

Los viajes se realizan de forma predominante hacia países reconocidos y con una imagen turística potente entre los consumidores españoles. No obstante entre los destinos de estancia concretos predominan los lugares poco conocidos. En concreto un $78 \%$ de los viajes incluyen lugares poco conocidos, mientras que un 57\% incluyen lugares must-see en el programa de la visita. Puede deducirse de ello que se pretende destacar el elemento «pionero» o incluso exótico en el viaje de turismo responsable. De todos modos un análisis detallado de los lugares visitados muestra que tan solo en un $42,7 \%$ de los viajes se visitan exclusivamente lugares poco conocidos o fuera de los circuitos turísticos habituales, mientras que en un $20,2 \%$ se visitan exclusivamente lugares must-see y en un $37,1 \%$ se combinan ambos tipos de destinos en un mismo viaje, por lo que podemos afirmar que la estrategia de seleccionar lugares con imagen de marca reconocible también está muy arraigada.

\section{II.3. ELEMENTOS PARA LA MOTIVACIÓN DE LA DEMANDA CONTENIDOS EN LOS CATÁLO- GOS DE VIAJE DE TURISMO RESPONSABLE EN ESPAÑA (2012)}

En este apartado se exponen los resultados del análisis de la presentación y descripción del viaje realizada por los propios distribuidores. Este tipo de análisis deja entrever el argumento discursivo con el que el viaje es presentado en el catálogo de turismo responsable para su comercialización y,por tanto, permite apreciar cómo se ven a sí mismos. La información extraída de los descriptores (título del viaje y resumen del mismo) permite apreciar la autodenominación del modo de viajar que cada entidad da a sus viajes de turismo responsable, así como distinguir las principales líneas argumentales que responden a la filosofía de viaje de cada entidad y que se utilizan como elemento para motivar la demanda potencial o para generar empatía con la misma. Finalmente se analiza el programa de vacaciones detallado para observar las prácticas diarias que se prevé realizar durante la estancia en el destino.

Las etiquetas que aparecen en el título de los viajes ofrecidos por las catorce entidades analizadas incluyen una autodenominación que refleja la filosofía inherente a cada tipo de viaje. Se observa un espectro de etiquetas que van desde las que contemplan un elemento recreativo (turismo, viaje, ruta) hasta las que lo excluyen parcial o completamente (estancias, voluntariado, brigadas). La definición de viaje predominante tienen un carácter mixto $(51,7 \%)$ (recreativo y alternativo), mientras que las definiciones únicamente de carácter alternativo $(31,4 \%)$ o recreativo $(16,9 \%)$ son menos abundantes. Las autodenominaciones del viaje concuerdan con la voluntad de diferenciarse de productos de turismo convencional. El componente de ocio solo se incluye de la mano de una eti- 
queta complementaria que lo reubica en una dimensión solidaria o responsable, razón por lo que se tiende a optar por denominaciones mixtas y a evitar los extremos del espectro.

El debate del discurso a través de las autodenominaciones puede completarse a partir del análisis de la recurrencia de las etiquetas usadas en el título del viaje. El término preferido como presentación del programa a realizar es el de «viaje» (aparece en el 33,5\% del total de los títulos del catálogo de viajes) mientras que el término turismo aparece en un $24,6 \%$ de los casos. No obstante ambas etiquetas aparecen siempre acompañadas de un «apellido» que lo matiza (responsable, solidario, sostenible, social, etc.), aunque la etiqueta viaje aparece sola en un $5 \%$ de los casos. De modo similar en el otro lado del espectro las etiquetas que se refieren al turismo alternativo tampoco acostumbran a aparecer en solitario (solo en un 3,9\% de los casos). En resumen, la etiqueta turismo se rehuye como denominación de la fórmula de viaje pero, debido a que se considera que el componente recreativo es básico, aparece combinada con etiquetas que adjetivan de forma significativa el viaje y permiten distinguirla de los viajes de vacaciones convencionales. Finalmente destacar dos aspectos más: que el viaje es la etiqueta más usada (probablemente para motivar el espíritu «viajero») y que las denominaciones puramente de carácter alternativo están poco representadas (posiblemente porque dan una imagen excesivamente alejada de los componentes de ocio y recreación que requieren unas vacaciones solidarias).

El resumen del viaje permite también ver como se perfilan las motivaciones de los mismos. Este descriptor define las prácticas básicas a realizar en el viaje, cosa que permite agruparlas en cuatro tipos básicos: juego, descubrimiento, reposo (Équipe MIT, 2002) y solidaridad. El descubrimiento es la principal práctica de los viajes de turismo responsable (presente en un $96,6 \%$ de los viajes), mientras que la práctica solidaria ocupa el segundo lugar $(41,6 \%)$. Mucho menos representadas están la práctica de reposo $(20,2 \%)$ y de juego $(6,7 \%)$. El leit motiv de los viajes de turismo responsable parece ser un tipo de vacaciones donde existe un contacto directo con el destino que permite el aprendizaje o intercambio cultural, combinado con la presencia de prácticas solidarias. En algunos casos se añaden también prácticas vinculadas con el reposo o con la actividad física, pero raramente como las prácticas dominantes del viaje.

Otro de los aspectos que inciden sobre la motivación es el carácter de autenticidad que se otorga a los viajes de turismo responsable. Es frecuente recurrir a la expresión «dar a conocer la realidad del destino» como aspecto destacado del programa de viaje. Ello se argumenta en base a la proximidad del contacto con la comunidad local y por el hecho que durante la estancia se dan a conocer las problemáticas, aunque éste tipo de actividad acostumbra a tener más un carácter formativo que de colaboración directa en proyectos o voluntariado.

Los elementos destacados en el descriptor resumen del viaje permiten apreciar también hacia qué modalidades turísticas se orienta preferentemente el viaje de turismo responsable (véase la tabla 4).

El resultado muestra una amplia gama de modalidades, cosa que podría explicarse porque se trata de viajes de larga duración que requieren una amplia variedad de actividades para dar cobertura a todo el tiempo de ocio. No obstante existe un enfoque principal orientado hacia dos elementos: el patrimonio cultural y el turismo comunitario o de contacto con la población local. Contrariamente, el turismo de voluntariado, el ecoturismo y el turismo deportivo y de acción aparecen mucho menos representados. Los viajes de turismo responsable se orientan a la visita cultural formativa e informativa. La importancia de la visita del 
Tabla 4

MODALIDADES DE TURISMO DESTACADAS EN LOS DESCRIPTORES DE VIAJES DE TURISMO RESPONSABLE, 2012

\begin{tabular}{|l|c|c|}
\hline Modalidad & Frecuencia & $\%$ \\
\hline Turismo voluntario & 35 & 39,3 \\
\hline Turismo comunitario & 53 & 59,6 \\
\hline Ecoturismo y turismo de naturaleza & 34 & 38,2 \\
\hline Turismo de patrimonio & 76 & 85,4 \\
\hline Turismo deportivo y de riesgo & 14 & 15,7 \\
\hline Total & 212 & 100 \\
\hline
\end{tabular}

Fuente: Elaboración propia a partir de los catálogos electrónicos y de las páginas webs de los distribuidores.

patrimonio (tanto cultural como natural) queda patente como un elemento fundamental en la visita turística, pero a diferencia de otros modelos, en el turismo responsable se incide en la importancia de dar a conocer el destino de forma directa a partir de los ojos de la comunidad receptora y compartiendo experiencias y vida cotidiana. El turismo voluntario queda en un segundo plano como modalidad, aunque por encima de modalidades más especializadas como el deportivo o el ecoturismo.

Es interesante analizar las modalidades que aparecen en los programas de viajes diferenciándolos según si domina el componente solidario, de intercambio cultural o más convencional. Para efectuar esta caracterización se ha distinguido entre los viajes según las prácticas turísticas dominantes. Se han establecido tres tipos básicos que corresponden al turismo responsable de tipo solidario (incluye tanto viajes de voluntariado como viajes donde son frecuentes las cooperaciones puntuales), los que incluyen un marcado componente de intercambio cultural (incluido el turismo comunitario y otras formas de contacto con la comunidad local) y los que no incluyen ni uno ni otro componente de forma predominante aunque los contemplen como propuestas complementarias en el viaje (vacacionales solidarios). Cada tipo básico de viaje de turismo responsable se ha puesto en relación con las modalidades de viaje que aparecen en sus descriptores para identificar qué modalidades caracterizan mejor a cada perfil básico de viaje de turismo responsable. Hay que tener en cuenta que en algunos casos en que la orientación es compartida (por ejemplo viajes de turismo solidario que contienen abundantes prácticas de intercambio cultural) resulta imposible asignarlos a una única tipología.

En primer lugar se advierte el predominio, desde el punto de vista de las prácticas realizadas, de los viajes de carácter vacacional solidario (38\% de los casos) y de los de intercambio cultural $(37,3 \%)$. Finalmente los viajes que incluyen como prácticas predominantes los elementos de solidaridad y voluntariado implican el $24,7 \%$ de los casos. Desde el punto de vista de las prácticas realizadas en destino en los viajes de turismo responsable se aprecia por tanto que existe una mezcla de componentes tanto de descubrimiento, reposo y solidaridad que dan el carácter diferencial a este tipo de viajes. La existencia de prácticas de ocio y recreativas justifican el viaje de turismo responsable y lo diferencian claramente de otros tipos de propuestas no turísticas.

Es también interesante destacar que existen algunos patrones similares en la frecuencia de aparición de las modalidades en cada tipología de viaje de turismo responsable. Por ejem- 
plo, el turismo de patrimonio es siempre la modalidad complementaria que aparece con más frecuencia, a excepción del caso de los viajes de tipo no solidarios, donde es la principal; el ecoturismo está presente en menos de la mitad de los viajes de cada tipología y el turismo deportivo es marginal en todas ellas.

No obstante se detecta también la existencia de algunas diferencias interesantes. Por ejemplo el tipo solidario conlleva menos presencia de la modalidad comunitaria $(45,71 \%)$ que en el tipo no solidario $(68,52 \%)$, mientras que en el de intercambio cultural la presencia de la modalidad de turismo de patrimonio es prácticamente idéntica a la del tipo no solidario (90,74\% y 90,57\% respectivamente). Además tan solo en el caso del voluntariado las diferencias son significativas entre el turismo no solidario $(0 \%)$ y el de intercambio cultural $(30,19 \%)$. Esta composición de modalidades permite hablar del carácter bimodal del producto de turismo responsable. Existen similitudes entre los tipos no solidario y de intercambio cultural, mientras que el turismo solidario tiene un patrón más diferenciado dado que apuesta por un tipo de turismo mucho más alejado del modelo de vacacionales tradicionales.

Otro elemento de análisis llevado a cabo ha consistido en clasificar las actividades que constan en los programas del catálogo de viajes de turismo responsable. En concreto se han contabilizado el número total de días en que se ha realizado un tipo de actividad determinada en el conjunto del programa de viaje. Esta información permite analizar la importancia que tienen las actividades específicas dentro del programa de viaje

A manera de síntesis comentar que en el conjunto de viajes de turismo responsable analizados pueden distinguirse diferentes tipos de viajes en función de las actividades realizadas predominantes (las que incluyen más del $40 \%$ del total de actividades programadas en los viajes de turismo responsable pertenecientes a un determinado tipo de modalidad). En el tipo de viaje basado en la solidaridad el mayor peso de actividades de viaje se centra en el turismo voluntario y comunitario. En el tipo basado en el contacto entre culturas el mayor volumen de actividades vacacionales se centra en el turismo comunitario y la visita a lugares de patrimonio cultural o natural. En el caso del tipo vacacional solidario el programa de viaje se orienta sobre todo a las visitas patrimoniales y de contacto o de convivencia con la comunidad local. Esta distribución de modalidades sugiere una tipología de viajes de turismo responsable donde el paquete solidario se introduce como elemento principal de la motivación de las vacaciones pero no en todos los tipos supone una práctica principal, puesto que en parte de los viajes se equiparan también con las relacionadas con el descubrimiento y en el caso del vacacional solidario es una práctica complementaria (véase la tabla 5).

Tabla 5

IMPORTANCIA DE LAS PRÁCTICAS TURÍSTICAS PRESENTES EN LOS PROGRAMAS DE VIAJES DE TURISMO RESPONSABLE, 2012

\begin{tabular}{|l|l|l|l|}
\hline Prácticas & Solidario & Contacto intercultural & Vacacional solidario \\
\hline Descubrimiento & Complementaria $(41 \%)$ & Principal $(47 \%)$ & Principal $(60 \%)$ \\
\hline Reposo & Minoritaria $(<5 \%)$ & Minoritaria $(<5 \%)$ & Minoritaria $(<5 \%)$ \\
\hline Juego & Minoritaria $(5 \%)$ & Minoritaria $(<5 \%)$ & Minoritaria $(7 \%)$ \\
\hline Solidaridad & Principal $(53 \%)$ & Principal $(48 \%)$ & Complementaria $(32 \%)$ \\
\hline
\end{tabular}

Fuente: Elaboración propia. 


\section{CONCLUSIONES}

El estudio consiste en un análisis exploratorio de las características del turismo responsable en España en 2012. Los resultados están limitados, por tanto, a la visión que ofrecen los catálogos en este momento concreto y a la muestra de distribuidores escogidos, por lo que no se recogen las posibles variaciones temporales del mismo ni el conjunto de la oferta. No obstante se considera que la muestra es significativa en tanto que recopila los principales distribuidores de turismo responsable que operan en España. El propósito de este trabajo es realizar una radiografía del momento actual por lo que se ve limitado a efectos comparativos y por las fuentes consultadas. Por ello en un futuro se prevé realizar una nueva investigación donde se pueda, ampliar otros tipos de catálogos, observar la evolución de las tendencias apuntadas aquí y ampliar la muestra a los distribuidores de otros países para poder comparar los resultados. Los resultados sobre la situación del turismo responsable en España obtenidos en este trabajo exploratorio son claros pero, al mismo tiempo, plantean nuevas preguntas que requieren profundizar en algunos temas clave. Entre otros aspectos será necesario profundizar sobre la valoración de los diferentes perfiles de demanda (motivación, satisfacción, decisiones de compra, etc.) acerca de los viajes de turismo responsable; analizar cuáles son los factores de localización que determinan la oferta de destinos, considerar qué importancia tiene la financiación pública en materia de cooperación con la creación de productos de turismo responsable y, especialmente, en su enfoque y orientación; o explicar qué consecuencias puede tener la previsible reducción de fondos de cooperación en los viajes de turismo responsable . Queda, por tanto, mucho recorrido y espacio para realizar nuevas investigaciones sobre esta temática. La principal aportación de este estudio ha consistido en la elaboración de un marco de interpretación sobre la creación de productos turísticos basados en la responsabilidad; un elemento que puede servir de apoyo a futuras aproximaciones en torno al turismo responsable, tanto desde el punto de vista de la oferta como de la demanda.

Los viajes de turismo responsable comercializados en España constituyen un producto con características claramente diferenciadas y con una imagen asociada a la solidaridad y la responsabilidad. No obstante existe una escasa segmentación de productos de viaje de turismo responsable, aspecto que puede dificultar la captación de nuevos consumidores o con perfiles diferentes a los actualmente existentes. A partir del análisis del contenido de los programas de viaje (modalidades, actividades y prácticas turísticas que contienen) se aprecia la existencia de tres tipos de viajes básicos de turismo responsable. El primer tipo, que denominamos turismo responsable de corte solidario, se vincula sobre todo a las actividades relacionadas con las prácticas de solidaridad y, de forma complementaria a la anterior, con las de descubrimiento. Esto se traduce en el predominio de las actividades próximas al turismo de voluntariado y al turismo comunitario, pero también, como complemento de las anteriores, de una presencia importante de turismo de patrimonio. El segundo tipo, que denominamos turismo responsable de intercambio cultural, se fundamenta también en las prácticas de descubrimiento y solidaridad. No obstante la fórmula es diferente puesto que pone el énfasis en el contacto con la comunidad local y en el turismo de patrimonio o de naturaleza a partes iguales. El tercer tipo es el turismo responsable de corte vacacional solidario. En este tipo se invierten los términos y las prácticas de descubrimiento son las principales (básicamente realizadas a partir de actividades basadas en la modalidad de turismo de patrimonio 
y ecoturismo), mientras que las de solidaridad (mucho más centradas en las modalidades de turismo comunitario que de voluntariado) son un complemento, y existe un cierto interés por las prácticas de juego (deporte, riesgo, acción, etc.). La distribución de los viajes totales de turismo responsable por tipos muestra un equilibrio entre los vacacionales solidarios y los de intercambio cultural (ambos representan 3/4 partes de la oferta total de viajes), mientras que el de tipo solidario puro tiene una presencia menor (cerca del 25\% del total de viajes).

En cualquier caso merece la pena remarcar que todas las combinaciones incluyen prácticas de ocio, aunque su densidad en el conjunto de programas de viaje varía según el tipo. Existe, por tanto, una gradación de prácticas de ocio que permite identificar cuatro subtipos de viajes de turismo responsable. Esta clasificación puede resultar de utilidad como marco para establecer estrategias de posicionamiento y comercialización dirigidos a diferentes segmentos de la demanda. En un extremo se situaría el subtipo turismo voluntario y de crecimiento personal, los programas de viaje del cual proyectan un imaginario centrado en la emulación del cooperante, donde los componentes de ocio son marginales y se conciben como un premio al esfuerzo y al compromiso personal. Este tipo de viaje permite ofrecer una aproximación atractiva al destino en términos de autenticidad y de compromiso personal, así como recrear experiencias de cooperación bajo el paraguas del viaje turístico, normalmente adecuadas para perfiles de demanda sensibilizados y/o que pretenden acercarse al mundo de la cooperación o del voluntariado. En el otro extremo encontramos el subtipo vacaciones con mensaje, donde el aspecto recreativo predomina sobre el resto y la solidaridad aparece en forma de pincelada en el programa de actividades. Este puede ser un formato de viaje interesante para introducir el turismo responsable entre los segmentos de población conscientes de la necesidad de responsabilidad social del viaje turístico pero que requieren grandes dosis de diversión. En un lugar intermedio se ubican el subtipo que denominamos turismo solidario de convivencia, donde las prácticas se basan fundamentalmente en la participación y en el contacto con la comunidad local; y el subtipo turismo de formación, en el que las prácticas se orientan hacia el conocimiento del destino más desde el punto de vista del aprendizaje informal que de la participación directa en cooperación o voluntariado. En estos casos la demanda potencial abarca desde los miembros de asociaciones y entidades no gubernamentales o personas con acentuado compromiso social, ideológico y político, hasta personas interesadas en el conocimiento de un destino a través de cauces no convencionales y personas que, sin la vocación o habilidades de los cooperantes profesionales, están interesadas en participar puntualmente y/o conocer directamente las tareas de cooperación al desarrollo o de solidaridad.

El perfil de viajes de turismo responsable español parece responder a estrategias que responden a su condición de nicho de mercado, con escasos proveedores en relación a su oferta y un grupo minoritario de demanda con motivaciones y necesidades vacacionales específicas y dispuestos a pagar un precio extra para adquirirlas. No obstante, si tenemos en cuenta la existencia de algunos subtipos de turismo responsable cuyos catálogos de viaje incluyen de forma predominante las prácticas de ocio, empiezan a verse síntomas de apertura hacia segmentos de mercado mayores. Este aspecto permite enlazar la creación de productos de turismo responsable con el debate ideológico acerca de la conveniencia de comercializar este tipo de viajes (Bramwell, Lane, McCabe, Mosedale, y Scarles, 2008). En todo caso ante un presumible crecimiento de la demanda de turismo responsable en los próximos años habrá 
que detenerse a analizar las implicaciones que pueda derivarse de esta situación. Entre algunos de los temas pendientes se encuentran, por un lado, la necesidad de reflexionar acerca de la capacidad del pequeño formato de viaje como elemento de sensibilización a gran escala social y acerca de cómo sensibilizar a públicos con intereses generalistas. Por otro lado, y a medida que los viajes de turismo responsable se afiancen entre el público, irá en aumento la necesidad de adaptar estos viajes a las exigencias de grupos sociales específicos propensos a consumirlos siempre que su experiencia les aporte novedad o sintonicen exactamente con sus motivaciones. Por ejemplo, actualmente son muy escasos los viajes planteados desde el punto de vista del género entre los catálogos analizados, a pesar de que las mujeres son uno de los segmentos más interesados en su consumo.

Una última batería de conclusiones se destina a comentar algunas consideraciones sobre el formato del viaje de turismo responsable. La narrativa de la mayor parte de catálogos de viajes reproduce el imaginario del viajero (lejanía, alteridad basada en el contacto directo con el otro, descubrimiento de una «realidad» desconocida, autenticidad, exotismo, carácter pionero, etc.) pero de forma controlada, e incluso estandarizada, para minimizar riesgos y ofrecer comodidad a la experiencia del viaje. A pesar de que las incomodidades puedan ser valoradas como un aspecto positivo de la experiencia de viaje por una parte de la demanda (Lepp, 2009), la mayor parte de los turistas prefieren un formato de vacaciones austero pero cómodo para los estándares occidentales. No obstante, el planteamiento del viaje de turismo responsable como forma de turismo alternativo y alejado del turista convencional no queda exento de algunas ambigüedades. La concentración de la oferta en un número limitado de países, la presencia de elementos que refuerzan el carácter de distinción social vinculado a la solidaridad, el impacto ambiental derivado de los desplazamientos a larga distancia, la fragmentación de las estancias que merma la capacidad de compresión y de intercambio cultural con la comunidad local, el carácter poco definido o no dominante del componente de solidaridad en algunos viajes o la ausencia de seguimiento de resultados y evaluaciones de proyectos son aspectos para la reflexión futura.

El turismo responsable supone una oportunidad para establecer puentes de solidaridad y para ejercer como palanca social para el impulso de proyectos de responsabilidad social al conjunto del sector turístico. En este sentido, trabajar en los productos de turismo responsable para llegar a un público más amplio podría ser un factor importante para eliminar algunas barreras de entrada a las agencias de viajes y para introducir cambios en el sentido ético y de responsabilidad moral al conjunto del sector turístico español. Actualmente la oferta de turismo responsable permite ofrecer vías para la sensibilización a la sociedad pero a pequeña escala y presumiblemente dirigida a un perfil de viajero con un mensaje ya previamente interiorizado. El reto más importante probablemente estriba en crear productos atractivos para nuevos segmentos de la demanda y, en la medida que esta demanda se vaya afianzando, establecer pautas y patrones de producto, de gestión y de compromiso con el destino que puedan ser usados como modelos para otros formatos de vacaciones.

\section{REFERENCIAS}

AGENCIA ANDALUZA DE COOPERACIÓN INTERNACIONAL AL DESARROLLO (2011): Memoria anual 2011. Sevilla, AACID. 
AGENCIA ESPAÑOLA DE COOPERACIÓN Y DESARROLLO (2011): Memoria anual de la financiación de la AECID a ONGD. Madrid. AECID.

AGÈNCIA CATALANA DE COOPERACIÓ (2011): Memòria de la Cooperació al desenvolupament de la Generalitat de Catalunya, 2011. Barcelona, ACA

ASHLEY, C., ROE, D., y GOODWIN, H. (2001): Pro-poor tourism strategies: Making tourism work for the poor: A review of experience. IIED.

BADDELEY, J., FONT, X., JAMAL, T., DREDGE, D., et al. (2011): «Barriers to tour operator sustainable supply chain management». Tourism Recreation Research, $\mathrm{n}^{\circ} 36(3), 205-$ 214.

BRAMWELL, B., LANE, B., McCABE, S., MOSEDALE, J., y SCARLES, C. (2008): «Research perspectives on responsible tourism». Journal of Sustainable Tourism, $\mathrm{n}^{\circ} 16$ (3), 3-6.

BUTCHER, J. (2003): The moralisation of tourism: sun, sand... and saving the world?. London. Routledge.

CAÑIZARES, M.C. (2013): «Sostenibilidad y Turismo: de la documentación internacional a la planificación en España «Horizonte 2020», Boletín de la Asociación de Geógrafos Españoles, $\mathrm{n}^{\circ}$ 61, 67-92.

DERNOI, L.A. (1988). «Alternative or community based tourism» en Global Conference: Tourism. A vital force for peace (AAVV), Montreal, The Conference, 91-95

EL DIEF, M., y FONT, X. (2010). «The determinants of hotels' marketing managers' green marketing behaviour». Journal of Sustainable Tourism, No 18(2), 157-174.

ÉQUIPE, M. I. T. (2002). Tourismes 1. Lieux communs. Paris: Belin.

FONDEVILA, J. F.; \& SOLIGUER, A. (2012). «Commercialization Formulae of the Responsible Tourism in Spain: Reality and Trends». I Congreso Internacional OCITUR 2012-Primer Congreso de Ocio y Turismo. Ocio y Turismo del XXI-Perspectivas de Futuro. Barcelona

FREY, N. y GEORGE, R. (2008). «Responsible tourism and the tourism industry: A demand and supply perspective en Responsible tourism: critical issues for conservation and development, (Spenceley, A., Ed.) London, Earthscan, 107-128.

FULLANA, P. y AYUSO, S. (2002): Turismo Sostenible. Ed. Rubes. Barcelona.

GARCÍA SAURA, P. J. (2010): «Turismo activo y medio ambiente: una implicación necesaria. Aspectos jurídicos». Cuadernos de Turismo, $\mathrm{n}^{\circ}$ 26, 153-176.

GASCON, J, y CAÑADAS, E. (2005): Viajar a todo tren: turismo, desarrollo y sostenibilidad. Barcelona, Icaria.

GODWIN, H. (2011): Taking responsibility for tourism. Oxford: Goodfellow.

GODWIN, H. (2012): «Ten years of responsible tourism: an assessment». Progress in Responsible Tourism, 2(1), 4-33.

GOMIS, J. M. (2009): Turismo justo, globalización y TIC. Barcelona. UOC.

KASIM, A. (2007): «Corporate environmentalism in the hotel sector: Evidence of drivers and barriers in Penang, Malaysia». Journal of Sustainable Tourism, nº15 (6), 680-699.

KEESE, J. R. (2011): «The Geography of Volunteer Tourism: Place Matters». Tourism Geographies, $\mathrm{n}^{\mathrm{0}} 13(2), 257-279$.

KELLY, I. (1997). «Study tours: a model for benign tourism?». Journal of Tourism Studies, $\mathrm{n}^{\circ} 8$ (1) $42-51$. 
LEPP, A. (2009): «Leisure and obligation: an investigation of volunteer tourists' experience at Kenya's Taita Discovery Center», Journal of Leisure Research, n 41(2), 253-260.

PALOMO, S. (1998): «La aportación del turismo al desarrollo económico de los países en vías de desarrollo.: El caso del mercado receptor de Bolívia». Estudios Turísticos, $\mathrm{n}^{\circ} 136$, 45-82.

PALOMO, S. (2006): «El turismo justo y la creación de sistemas de producción de servicios turísticos responsables». Estudios Turísticos, n $168,7-46$.

PALOMO, S. (2010): «Nuevos planteamientos para la Concepción Internacional al Desarrollo turístico en España: Orientaciones desde una evaluación intermedia del Plan Director de Cooperación 2005-2008», en Turismo, cooperación y desarrollo: Actas I Congreso COODTUR (Nel·lo, M. ed.), Tarragona, URV, 23-24.

PÉREZ, M. (2004): Manual del Turismo Sostenible. Como conseguir un turismo social, económico y ambientalmente responsable. Ed. Mundi-Prensa. Madrid.

RIVERA, M. y RODRÍGUEZ, L. (2012): Turismo responsable, sostenibilidad y desarrollo local comunitario. Universidad de Córdoba. Córdoba.

TORRES, A. (2010): «Sostenibilitat i modalitats turístiques. Una anàlisi de casos a Catalunya». Documents d'Anàlisi Geogràfica, no ${ }^{\circ}$ 56/3, 479-502.

TORRES, A y LÓPEZ PALOMEQUE, F. (2011): «The growth and spread of the concept of sustainable tourism: The contribuiton of institutional initiatives to tourism policy». Tourism Management Perspectives, $\mathrm{n}^{\circ}$ 4, 1-10.

URRY, J. (2000). The tourism gaze. London. Sage.

VERA, J.F. (Dir.) (2001): Planificación y gestión del desarrollo turístico sostenible. Propuestas para la creación de un sistema de indicadores. Institut Universitari d'Alacant. Alacant.

WEARING, S. (2001). Volunteer tourism: Experiences that make a difference. London. CABI.

WEARING, S.L., \& WEARING, M. (2006): «Rereading the subjugating tourist in neoliberalism: postcolonial otherness and the tourist experience». Tourism Analysis, $\mathrm{n}^{\circ} 11$, $145-162$. 